\title{
Networks of Influence: Implementing Politically Sustainable Multinational Stakeholder Strategies
}

\author{
Lite J. Nartey \\ Ph.D. awarded by the University of Pennsylvania, The Wharton School, May 2012
}

\section{NAVIGATING UNCERTAINTY IN THE NONMARKET ENVIRON-} MENT (Baron, 1995; Baron \& Diermeier, 2007) has been a long-standing focus of scholarship at the nexus of international business and multinational strategy as the nature of this environment has significant implications for a firm's reputation and ultimately, survival. Navigating the nonmarket environment-specifically, the "social, political, and legal arrangements that structure the firm's interactions outside of, and in conjunction with, markets" (Baron, 1995:49)—includes managing and influencing interactions with the public, stakeholders, government, the media, and public institutions (Baron, 1995:47) who shape the nature of the environment firms must operate within. Consider the example of two gold mining firms, one operating a mine in post-communist Romania and the other operating a mine in the post-civil war environment of the Democratic Republic of Congo, where both mines have similar gold ore quantities, similar geological and technical requirements for the extraction of the gold, and both mines are the single assets of two Canadian mining firms. Technical expertise would predict that both firms would reach production at the same time. However, as of 2012, after roughly 10 years of operations, only the mine in the Democratic Republic of Congo had reached production; the Romanian mine still does not have the license to operate! This difference in outcome is contingent on how these firms managed their nonmarket environments.

In this dissertation, I explore the firm's ability to manage the nonmarket environment, specifically, the political, social and economic actors who have a stake in their operations, i.e., their stakeholders (Freeman, 1984). Using the tools of network theory, as well as insights from the entrepreneurship, social psychology, and civic or political participation literatures, I present a stakeholder influence strategy for firms to navigate nonmarket uncertainty by engendering cooperative relations, increasing tie formation and minimizing conflict with their stakeholders. I explore this network-based influence strategy within an industry characterized by significant nonmarket uncertainty-the global gold mining industry-using a novel, hand-coded dataset of 51,754 stakeholder events linking 4,623 unique stakeholders of a population of 19 gold mining firms listed on the Toronto Stock Exchanges which operate 26 mines in 20 countries.

Within the global gold mining industry, nonmarket uncertainty ranges from hostile relations and adverse interventions by governments- such as, sudden stop-work orders, denial of security and work permits, adverse tax or regulatory changes, or outright expropriations of assets - to interventions orchestrated by actors from civil society — such as, sophisticated political strategies of nongovernmental coalitions, violent and nonviolent protests, employee strikes and walkouts, or acts of sabotage. These adverse interventions by both governments and civil society actors can have detrimental impacts on firm operations. They often result in closures, operational delays, and outright loss of assets and can cause irreparable damage to that firm's reputation, thus adversely affecting the firm's financial returns. For example, Newmont's loss of the $\$ 5$ billion Conga gold and copper project in Peru due to adverse stakeholder action.

Understanding the need to engage stakeholders, and in a bid to "win the hearts and minds" of external stakeholders, firms operating in hostile nonmarket environments often engage in corporate philanthropy or corporate social responsibility activities. Examples of these activities include the building of hospitals, schools, libraries, town halls, as well as the more politically-motivated and controversial expenses such as the building of private residences and palaces for government officials, and the loan of private planes to strategic political actors. This strategy can result in significant outlays of financial and other resources_-for example, firms in the extractive industries reportedly spent upwards of $\$ 500$ million annually on corporate social activities and expenses (Wells, Perish, \& Guimaraes, 2001). Shell alone spent $\$ 104$ million on social investment in 2004. These significant outlays of financial and other resources however often have uncertain financial and operational returns due to the fundamental disconnect between the financially-based exchange mechanism of firms and the sociological exchange mechanism of stakeholders.

While the financial mechanism of exchange for firms is largely rational with objective quantifiable costs, benefits and inputs and outputs, the socially-based exchange mechanism of stakeholders is not monetary nor quantifiable and is often not rational but rather based on subjective intangible factors such as trust, social capital, reputation, expectations and biases (Zandvliet, 2004). Often, business in nonmarket environments fraught with uncertainty is contingent on transforming perceptions of identity from foreign extractor to local community member. Such a focus leads to very different recommendations on which stakeholders to approach and how to engage with them. I seek to bridge 
the divide between the rational and social exchange perspectives not through a limited and often ineffective corporate social responsibility approach, but rather through a stakeholder influence strategy by which the firm's strategic formation of ties with stakeholders can protect and enhance the firm's reputation and cooperation with stakeholders, while minimizing or undermining conflictual stakeholder relations.

I use the concepts and tools of network theory, as well as insights from the entrepreneurship, social psychology, and civic or political participation literatures, to explore the links between the existing network structure of relationships between a foreign firm and stakeholders in the nonmarket environment, or the strategic choices made by the firm to alter that stakeholder network structure, and the subsequent development of the stakeholder network. The goal of this stakeholder influence strategy for firms is to strategically form cooperative ties while minimizing or undermining conflictual ties with stakeholders, which enhances the firm's reputation and has important financial and operational im- lations with stakeholders. I ground this influence strategy using three metaphors: (1) networks as pipes (Podolny, 2001), i.e., that the firm's position within the stakeholder network affords it information benefits and impacts the firm's subsequent relations with stakeholders, (2) networks as prisms (Podolny, 2001), i.e., that the stakeholder with whom the firm connects and the nature of the firm's engagement with stakeholders, affords it reputational benefits and impacts that firm's subsequent relations with stakeholders, and (3) networks as structures (Kahler, 2009), i.e., that because of the interdependencies and endogenous network evolutionary dynamics among stakeholders themselves, firms seeking to gain such information and reputation benefits should be wary of exposing themselves to preexisting conflict among stakeholders or fostering conflict by forming asymmetric relations with and among stakeholders.

This paper seeks to augment our understanding of how firms can strategically manage stakeholders and thus favorably shape their nonmarket environments. While scholars of nonmarket strategy and international business have employed market-based mechanisms to mitigate uncertainty in the nonmarket environment, scholars of stakeholder theory have sought to understand relations between firms and stakeholders from a largely normative position, and firms themselves in practice have sought to mitigate nonmarket uncertainty through acts of corporate social responsibility and philanthropy without a full understanding of how to engage with stakeholders. In this first plications. This dissertation comprises three paper chapters (one theoretical and two empirical). The theory paper is the foundational article which outlines an integrated nonmarket stakeholder influence strategy for firms. I test the propositions of this foundational article in the two empirical papers.

\section{Paper 1: Networks of Influence: Balancing Positional Benefits and Costs in Stakeholder Engagement Strategies}

The first paper is a theory paper in which I develop a network-based theory of influence for firms to strategically form ties with stakeholders. This stakeholder influence strategy includes specific testable propositions that link firm, stakeholder or network characteristics to the degree of conflict and cooperation exhibited by stakeholders toward the focal firm or each other. This stakeholder influence strategy is positioned within the stakeholder, civic and political participation literatures and uses network theory and concepts to explore how the firm's strategic position within the network of stakeholders affords it positional benefits of information and reputation, while also highlighting the costs of exposure to pre-existing conflict and the fostering of conflict through asymmetric relations.

The goal of this paper is to outline a sociopolitical influence strategy for firms to navigate complex political environments and improve re- paper, I use the literatures on civic and political participation, and the tools and concepts of network theory to identify non-market strategies that generate the greatest returns to firm corporate social responsibility activities and stakeholder engagement practices in terms of information and reputation benefits as well as garnering political and social support.

\section{Paper 2: Networks of influence: Pipes and Prisms of Political Influence}

The second paper explores empirically how firms manage the two types of uncertainty within the nonmarket environment-egocentric uncertainty (where the focal firm is uncertain about the qualities of the stakeholders within the environment), and altercentric uncertainty (where stakeholders are uncertain about the qualities and products of the firm) (Podolny, 2001). I use tools and insights from network theory to build upon extant insights and understandings of how best to manage egocentric and altercentric uncertainty (Podolny, 2001) and I compare the efficacy of the ex ante strategies that the firm can use to manage both egocentric and altercentric uncertainty. I hypothesize that through strategic network positioning that affords it information, the firm can manage its egocentric uncertainty; and, by managing how it is perceived through its associations, the firm can also manage stakeholders' altercentric uncertainty. Of course, the management of both types of uncertainty is not without cost and therefore, an important 
issue is to understand which type of uncertainty should be the primary focus of firms in highly uncertain nonmarket environments. My findings suggest that the key determinant of an increase in cooperation and tie formation within the stakeholder network is the focal firm's ability to mitigate altercentric uncertainty by forming ties with high status, cooperative stakeholders and ensuring reciprocity in these relationships through joint activity.

This second paper builds upon extant work exploring factors that mitigate egocentric and altercentric uncertainty (Podolny, 2001) and empirically tests these factors within the global gold mining industry-an industry rife with political and social tension among firms and diverse stakeholders. Egocentric uncertainty is mitigated by access to information through structural holes while altercentric uncertainty is mitigated by high status (Podolny, 2001). I use a network lens to explore additional factors of the firm that afford it information benefits (structural holes and network range), and I also explore factors of the stakeholders with whom the firm is associated that may afford the firm reputational benefits of high quality (i.e., the degree of cooperation, status and reciprocation in joint activity of the stakeholders to whom the firm is connected). The dependent variables of interest in this paper are (1) the degree of conflict or cooperation between the focal firm and stakeholders and (2) the number of ties formed, and thus the level of analysis is at the level of the dyad. The insights from this paper contribute to extant work on strategies to mitigate egocentric and altercentric uncertainty by exploring network-based information and reputation mechanisms on the mitigation of these two types of uncertainty.

\section{Paper 3: Networks of Influence: Homophily and Triadic Closure in Stakeholder Networks}

In the third paper I use insights from Simmelian (Simmel, 1950) and Balance (Cartwright \& Harary, 1956, Heider, 1958) theories to explore empirically the relationship between dyadic structure and triadic closure among networks of actors in the sociopolitical context. For each triple of actors forming an open triad, I explore how the homophily (or similarity) of the structural characteristics of the three actors comprising a triad impact the likelihood of that triad closing. I outline hypotheses of the homophily of four characteristics of the actors in the triad-access to resources, status, likeability and number of ties (popularity) —on the likelihood of a tie forming that closes the open triad. These four characteristics differ on whether their derived benefits are contingent on the dependence between actors and are therefore zero-sum outcomes (i.e., access to resources and status) or are not contingent on dependence between actors and are therefore not zero-sum outcomes (i.e., likeability and popularity).
I hypothesize that triadic closure is more likely when the actors of a triad have a greater difference in the characteristics contingent on the dependence between actors (access to resources and status), and greater similarity or homophily in the characteristics that are not contingent on the dependence between actors (likeability and popularity). Holding constant the quality of existing ties (i.e., strength of the ties), symmetry of relations in the existing dyads, reciprocity of relations in the existing dyads, and the number of common others actors in existing dyads are connected to, I find that a link that closes an open directed triad is more likely when the actors of the triad have different access to resources, and different status, but that link is more likely when actors have similar numbers of ties to other actors. I also find that likeability among actors in the triad has no impact on the likelihood of closing that triad. By exploring how the characteristics of actors in a network affect network dynamics, the insights of this third paper exploring triadic mechanisms add to our understanding of the contingent factors and mechanisms that affect network evolutionary dynamics. The outcome I explore in this paper, triadic closure, is also an underexplored network outcome which is of strategic importance to firms seeking to understand and manage their relations with stakeholders and the dynamics among stakeholders themselves as a firm that does not understand evolutionary dynamics may find its attempts to influence specific stakeholders thwarted or undone by unexpected changes in the structure of ties.

My empirical papers test the relationships among firms and stakeholders in the global gold mining industry using a novel database of 51,754 stakeholder events linking 4,623 unique stakeholders of a population of 19 publicly traded gold mining firms listed on the Toronto Stock Exchanges (TSX) which operate 26 mines in 20 mostly emerging economies. The gold mining industry is a particularly salient context for this study because gold mining is widely considered one of the most socially irresponsible and environmentally rapacious industries (Humphreys, 2001). Therefore, stakeholders (e.g., multilateral agencies, multiple levels of governments, NGOs, cultural or religious groups and firms or in-

\section{(s) The gold mining industry is a particularly salient context for this study because gold mining is widely considered one of the most socially irresponsible and environmen- tally rapacious industries.}

dividuals with an economic stake in the mine or the community) are relatively more active in their relations with firms. Thus, the impact of firm strategic network-building and stakeholder engagement strategies may be greater in this industry. While this study is conducted in the global gold mining industry, the theories underlying the strategies are garnered from a wide range of literatures and have been applied in 
various contexts. I therefore argue that the findings of this dissertation are generalizable to both foreign and domestic firms whose operations are highly subject to stakeholder control and action, i.e., foreign and domestic firms operating in environments and industries characterized by high nonmarket uncertainty and risk.

\section{Implications / Contributions}

While the network literature and network concepts are well-established, the networks I explore are conceivably and possibly structurally different from those used by network scholars. Extant work employing networks in the strategy literature primarily employ alliance data, while social network scholars often use email data, friendship data, and simulations to understand network dynamics. Conversely, the networks I explore in this dissertation are based on media-reported, dynamic, multiplex relations among diverse political, social and economic stakeholders within the global gold mining industry and are thus structurally different from the networks explored by alliance, strategy, and social network scholars. The application of network tools and concepts within this dynamic industry environment is an important means to explore

lished network tools and concepts in an understudied and novel network environment defined by complex and dynamic relations among a diverse set of actors. I contribute to the stakeholder literature by offering a network-based theoretical approach to instrumental stakeholder theory, and test this within a novel empirical industry setting. Further, through the use of this novel stakeholder relations dataset, I move from measuring at a corporate level whether a company is categorized as being more or less responsible according to some (self-reported) standards, principles or audits to a more objective measurement approach using event data at the stakeholder level on how stakeholders themselves perceive the firm.

This dissertation also has important implications for international business (IB) and strategy education, as well as for business practice and policy. The importance and relevance of the nonmarket environment and stakeholder engagement theories for firm strategy cannot be underscored, especially in the current global environment. This suggests a greater need for inclusion of these theories in general IB and strategy courses and materials at the undergraduate, MBA and Executive Education levels to furnish future and current managers with the tools necessary to effectively manage the nonmarket environment. Critically, while scholarly research on the nonmarket environment is not novel, the dynamic nature of the political, social and economic changes in the global environment offers a rich and fruitful area for future academic scholarship. Therefore, the inclusion of these theories and the necessary tools to enable deeper empirical and theoretical inquiry into courses at the doctoral level is essential to ensure research that is relevant to the current global business environment. For policy makers, insights garnered from research on firm-business-government and civil society

the contingencies and antecedents of network concepts in highly uncertain nonmarket environments.

Together these three papers create a theoretical and empirical base for strategic analysis of firms' interactions with stakeholder networks. They combine a firm-centered perspective of outreach to stakeholders with a structure-centered perspective of triads and balance together forming the building blocks of an understanding of how a firm can best improve its position in a dynamically evolving stakeholder network. The importance of such a strategic analysis of stakeholder networks and relations with firms is due to the important financial and operational implications of these strategies. By understanding who the stakeholders are and strategically forming ties to engender cooperation and reduce conflict with these stakeholders, the firm favorably shapes its nonmarket environment to facilitate market-based operations and benefits.

I contribute to the political risk and international business literatures by applying network tools to better define the political nonmarket environment for firms in terms of the political, social and economic stakeholders who can adversely impact, or benefit the firm and put forward and test hypotheses for firms to favorably manage their nonmarket environments. I contribute to the network literature by exploring estab- interactions is important for shaping policies that create enabling and sustaining environments for firms, but is also critical for informing the creation of policies that protect social value for stakeholders.

\section{References}

Baron, D. P. 1995. Integrated Strategy: MARKET AND NONMARKET COMPONENTS. California Management Review, 37(2): 47-65.

Baron, D. P. \& Diermeier, D. 2007. Strategic Activism and Nonmarket Strategy. Journal of Economics \& Management Strategy, 16(3): 599-634.

Cartwright, D. \& Harary, F. 1956. Structural balance: a generalization of Heider's theory. Psychological Review, 63(5): 277-93.

Freeman, R. E. 1984. Strategic management: A stakeholder approach. Boston: Pitman Publishing.

Heider, F. 1958. The Psychology of Interpersonal Relations. New York: Wiley.

Humphreys, D. 2001. Sustainable development: can the mining industry afford it? Resources Policy, 27(1): 1-7. 
Kahler, M., (Ed.). 2009. Networked Politics: Agency, Power, and Governance. Ithaca, NY: Cornell University Press.

Podolny, J. M. 2001. Networks as the Pipes and Prisms of the Market. American Journal of Sociology, 107(1): 33-60.

Simmel, G. 1950. Triad.In Wolff, Kurt H., (Ed.), The sociology of Georg Simmel. New York: Free Press.

Wells, J. B., Perish, M., \& Guimaraes, L. 2001. Can Oil and Gas Companies Extend Best Operating Practices to Community Development Assistance Programs?, Society of Petroleum Engineers (SPE) Asia Pacific Oil and Gas Conference and Exhibition, 17-19 April 2001. Jakarta, Indonesia: Society of Petroleum Engineers Inc.

Zandvliet, L. 2004. Conflict Prevention and Reconstruction: Redefining Corporate Social Risk Mitigation Strategies: The World Bank, Social Development Note \#1.

Lite J. Nartey is an Assistant Professor in the Sonoco International Business Department, Darla Moore School of Business, University of South Carolina. Her research explores the relationships, contingencies, and dynamics among multinational firms, governments and civil society actors and the implications of these dynamics on firm performance. Her work has been recognized for several awards and nominations including finalist for BPS, IM and ITC Division Dissertation Awards at AOM 2013, and second prize, Industry Studies Association Dissertation Award. Her work is also forthcoming in the Strategic Management Journal. 